\title{
An Exploration of Teaching Class of Mixed Ability
}

\author{
DUAN Lifang \\ Dehong Teachers’ College, Yunnan, China \\ SHI Yun \\ Chuxiong Teachers' College, Yunnan, China \\ WANG Yiyun \\ Dehong Teachers’ College, Yunnan, China
}

\begin{abstract}
There has been a long time of debate between the two teaching approaches of homogenous grouping and heterogeneous grouping. Here in the essay, we explored both of the two teaching approaches in Yunnan Province of China whereas the puzzle lies in the question of which method can achieve a relatively-better result in English classes of Yunnan. Some possible solutions are promoted based on the data and analysis collected from a survey.
\end{abstract}

Keywords: mixed ability, homogenous grouping, heterogeneous grouping, English teaching

\section{Introduction}

Today, English-teaching for non-English major students in normal universities and even junior colleges in China faces a tremendous challenge of a range of mixed levels. So, how to deal with the situation makes great sense in improving the comprehensive teaching efficiency. Level teaching based on language proficiency (homogenous grouping) can be explained as grouping students just in a single class that has the same language ability or grouping students from the whole school in terms of their English performance in exams, such as the College Entrance Examination or their first English test after enrolling. Mixed group teaching (heterogeneous grouping) means students with different ability, interest, and habits are grouped together, mixing up the strong students and relatively weak students. There has been a long time of debate between the two teaching approaches. Here in the essay, we explored both of the two teaching approaches in Yunnan Province of China whereas the puzzle lies in the question of which method can achieve a relatively-better result in English classes of Yunnan. Some possible solutions are promoted based on the data and analysis collected from a survey.

\section{Literature Review}

In terms of Teaching of Mixed Ability Class (MAC), there has been a long time argument on whether or not dividing the pupils based on their language competence. Usually, in one EFL class, it is not escapable that teacher has to deal with students of all kinds with different language prior knowledge, learning habit, thinking

DUAN Lifang, master, lecturer, School of Foreign Languages, Dehong Teachers' College, Yunnan, China. SHI Yun, master, lecturer, School of Foreign Languages, Chun Xiong Teachers' College, Yunnan, China. WANG Yiyun, master, lecturer, School of Foreign Languages, Dehong Teacher's College, Yunnan, China. 
patterns, interests, cultural background, etc. then the teacher would stay in dilemma to cope with in terms of setting teaching goals and designing teaching process, either to focus on the more advanced students ignoring the rest or address the less able learners at the risk of boring the more able ones as it seems difficult to deal effectively with this situation.

This debate also happens in academic researches and scholars. On the one hand, those who support dividing mixed ability class based their language levels (level teaching) claim that homogeneous grouping (HG) can promote and encourage both the high level group and low level group to learn actively, suggesting that students of different background and abilities can be gathered in groups of same ability thereby facilitating instruction (Slavin, 1987). The reason is that teachers of MAC can increase the pace and raise instruction level for high achievers whereas low level students can enjoy individual attention (Ansalone, 2000). Many other scholars, such as C. L. Kulik and J. A. Kulik (1982) and Slavin (1987), Marsh (1987), Allan (1991), and more recently Mulkey (2005) stood in line with homogeneous grouping, finding benefits from aspects of meta-analyses of studies, self-evaluation, modeling behavior (as cited in Xanthou \& Pavlou, 2008).

On the other hand, in the last quarter of the 20th century, homogeneous grouping has been criticized severely, because it stigmatizes lower ability students, offering them inferior instruction. Matthews (1997)'s relevant research found that gifted students are more diverse than they are homogeneous due to learners' interest, learning style, and social or emotional development. Other researchers also stated that level teaching may hurt the self-esteem and aspiration of low ability students and therefore decelerate their academic progress. The view were justified and supported by Mickelson (2000), Ireson and Hallam (1999), Gamoran (1987), Ansalone (2001), Hallinan (1994), Van der Veer and Valsiner (1991), and Scherer (1993) (as cited in Xanthou \& Pavlou, 2008).

What's more, a more favorable view of MAC teaching in recent age is heterogeneous grouping $(\mathrm{HeG})$ based on cooperative learning. The majority of scholars believe that

by creating mixed-ability groups, we send the compelling message that everybody is expected to work at the highest possible level as high and low ability students' deal with the same challenges. Disadvantaged pupils are at reduced risk of being stigmatized and exposed to a “dumped-down” curriculum in a mixed-ability setting. Teachers' expectations for all pupils are maintained at higher levels and less able students have opportunities to be assisted by more able peers. (Xanthou \& Pavlou, 2008)

R. Johnson and D. Johnson (1987) and Manlove and Baker (1995) pointed out that heterogeneous grouping can offer more assesses to learning opportunities and created effective learning environment. More scholars focus on the advantages of peer learning that would facilitate interaction between low ability students and high ability students, hence contribute to language development of all levels of learners, which indicate that learners of different abilities produce more in mixed ability pair and group work by helping one another to overcome cognitive obstacles. Some other relevant studies also conducted by O’Donnell (1985) and Liu and Hansen (2002), referring written task and format (as cited in Xanthou \& Pavlou, 2008).

To draw a conclusion, the divisions of how to teach MAC stay in a dilemma. Though both homogeneous and heterogeneous grouping are credited by their own advantages in teaching, more supportive researches tend to favor heterogeneous grouping because within a communicative and collaborative learning environment, heterogeneous grouping can make up the shorts of the frustration and low-esteem to learners caused by level 
teaching, more learning opportunities and interaction created and promote learning effectiveness in group of mixed abilities

\section{Investigation}

\section{Investigation Targets}

Here in Yunnan Province of China, mixed ability teaching is also a problem that all English teaching need to face. How will the two approaches of teaching, namely, homogenous grouping and heterogeneous grouping, are completed in three colleges of Yunnan Province. A questionnaire is made for Chinese teachers. Seventy-eight Chinese teachers who teach college English for non-English majors were investigated in total. The main purpose is to explore these following questions:

A: Are there homogenous grouping and heterogeneous grouping complemented in Yunnan Province? If so, how is the feedback?

B: What is the attitude Chinese teacher generally think of the two ways of teaching? Positive or negative?

C: Are there any possible solutions for Chinese teachers to solve the problem of mix-ability?

\section{Result of Investigation and Analysis}

Among 78 teachers who are surveyed in the questionnaire, eight teachers teach English majors, 24 teachers teach non-English majors, and 46 teachers teach both. According to the result of the questionnaire, the majority of teachers surveyed are facing the same circumstance: The language levels of students in one class are always different. As for the difficulties in such classes, more than $85 \%$ teachers think they cannot meet the demands of different students; $59 \%$ teachers think they are not able to organize classroom activities well; some of them (44\%) think they cannot assess students' work fairly.

When asked how much do they know about English level teaching? And have they had experience of level teaching? Most of them know something about it; however, they do not have such experiences. Twenty percent of them have heard but know little; more than $10 \%$ of them know much about level teaching and had such experience. More than $12 \%$ of them once had such experience. More than half (78\%) of the teachers surveyed support level teaching and only a few (8\%) are against this kind of teaching. Nearly half of them state that level teaching has great influence on their teaching initiative. Twenty-six percent of teachers feel stressful about level teaching while more than half of them do not have such feeling. As for the impact of level teaching on the relationship between students and teachers, $17 \%$ of them think that there is huge influence on the relationship between students and teachers; $23 \%$ of them think there is no influence.

How to teach the students with mixed levels? Nearly a third of these teachers who are surveyed use teacher-led instructional methods, while others adopt the following approaches: collaborative learning, task-based teaching, and flipped classroom. More than $40 \%$ of teachers occasionally group students according to their various interests and learning goals, while more than $50 \%$ of them rarely or even never do so. Twenty-one percent of teachers who are surveyed often set different learning goals for students in the same class, more than $55 \%$ of them occasionally do like this. The survey also shows that almost $80 \%$ of teachers think it is a good idea to ask the learners with mixed levels to answer different questions. But $5 \%$ of teachers do not think so, while the others are unsure about its appropriateness. How can teachers keep track the students' learning outcomes? Most of the teachers (86\%) accept that students display in the diversified forms: to demonstrate in the classroom, to communicate by WeChat or QQ, by E-mail or to submit paper assignments. 
To improve the language level of students with different abilities, the teachers surveyed hold their opinion that the language teachers should have strong observation ability, extensive knowledge, and sense of responsibility and love.

So, how can college English teachers realize effective teaching? How does college English teaching not only satisfy every student's need but also comply with the law of every student's development to guarantee that every student can make progress? These are urgent problems to be solved.

\section{Possible Solution on Mixed Abilities Classroom (MAC)}

As researchers and language teachers, the question to adopt the MAC, namely, to arrange language learners of varied abilities and competences in a classroom or group and teach students according to their language proficiency, is not a easy one. Different teachers may hold different beliefs and theories.

For language teachers of MAC, their approach can be justified by the following reasons as:

Equality. Both educators and language teachers should give students equal chances to develop their language potentials and proficiency even though students differ in these areas. Any student can make his progress at his own pace by learning to work in the group with help either of the teachers or from other classmates.

If students need to be classified into different level-learning groups, a problem will arise alongside: How can the teacher accurately achieve this complicated classification? What are basic standards and criteria which can be applied to his classifying? The reason is by language learning, it means the overall skills learning which involves speaking, listening, reading, and writing as well as different lexical knowledge learning, which consists of learning the knowledge about language, such as pronunciation, spelling, collocation, grammar, etc. The likeliness can be that a teacher is to find a student in his class who may be good at speaking but relatively poor in reading or vice versa. Since no test can be taken as the exact media or tools for steaming the students. Tests can neither lead to a fruitful, reliable learning outcome.

Equality brings about sense of belonging for the learners in the classroom. Hierarchy, by contrast, theoretically can push students' learning motivation and participation, especially for top stream students in the short run. However, learning by nature, is not meant to beat others, to stand high in the class for the long run. Learning a language to a good proficiency level is a time-consuming, lasting long process. The case is that if the learners' performances are largely spurred by external motivation, the learning process can be a fluctuating one.

Even though students' motivations fall into mainly two different categories: extrinsic and intrinsic one, the research shows that successful learning is largely relevant to, intrinsic motivation. By its definition, extrinsic motivation refers to the one coming from outside of the learners. It may be the promise of a reward or the threat of sanction. However, the counterpart, intrinsic motivation is the motivation that springs from within the learners, which is the stable and more decisive. It is the driving force for the learners to overcome the difficulties in learning. For this motivation, the language learners actually enjoy the process of acquiring and using the new language. In general, it plays a relatively bigger part in language learning process and general outcomes.

When learners feel that they are offered the equal chance to be exposed to the target language learning process and are given equal attention from the teacher, the majority students will naturally work out their learning strategies that best suit themselves and their learning models. The strong learners will become the 
examples and facilitators for the weak learners. When learners feel secure and accepted in learning, the interaction for language learning can truly be initiated.

Collaborative learning. Collaborative learning is a situation in which two or more people learn or attempt to learn something together. Unlike individual learning, learners engaged in collaborative learning relay on each individual's resources and skills, such as asking one another for information, evaluating one another's ideas, etc. More specifically, collaborative learning is based on the model that knowledge can be created and transferred within members' active interaction by sharing experiences and take on asymmetric roles. Collaborative learning emphases environments-creating which learners engaged in. A common task where each individual depends on is accountable to each other. Collaborative language learning may take forms of face-to-face conversations and online discussions, chat rooms, etc. Language learners can learn efficiently when groups of students work together to search for understanding the text, meaning of new words, or solutions to problems.

The point we want to make here is collaborative learning and peer learning can happen hand by hand to some degree, which can be overlapped. Collaborative learning is more about how learning happens, its ways, its settings that learning occurs while peer learning is more about the doers, the members in the learning process.

Authentic language environment. The ultimate goal of language learning is for language use. In the real world, communication is not only for the people gifted for language, good for speaking clearly and to the point, but also for some people who may be quick at thinking and resourceful with information. This is the reason why language learners should be mixed up to learn basic skills in communication while learning to be good listeners with understanding the speaker and speakers with predictions that listeners is likely to confront various problem for the reason of information gap. With mixed abilities classroom, teacher offers chances of learning environment, which shares a lot in common with the real world communication.

\section{Conclusion}

When we say students of low ability and high ability, these concepts are static and rigid. Learning is a dynamic process with numerous changes and learners' adjustment involved. This changing process can be attributed to learners' differences and their different learning styles.

Learners are born with great differences in their abilities; some are strong with linguistic potentials, some with logical thinking, some with good ears for sound and mime the pronunciation, some with strong intrapersonal skills, which are helpful for interaction and communicative learning. Learners apply to varied learning styles in learning a foreign language. Audial learners and visual learners use different strategies in acquiring a language. Audial learners relay in a large part on hearing the language while visual learners will learn a lot by reading the written language. Mixed abilities classroom can create a learning environment which allows different learning patterns and peer learning happen naturally.

For mixed abilities classroom, the suggestions for teachers can be the following as: (1) offer multitude of choices of learning approaches and activities for students; (2) be supportive rather than judgmental to students; (3) attach more importance to students' learning process than to the outcomes; and (4) cultivate students' thirst for learning a language intrinsically rather than extrinsically. 


\section{References}

Ansalone, G. (2000). Keeping on track: A reassessment of tracking in the schools. Race, Gender and Class, 7(3), 1-25.

Dudley, E., \& Osváth, E. (2015). Mixed-ability teaching. Oxford: Oxford University Press.

Johnson, R., \& Johnson, D. (1987). How can we put cooperative learning into practice? Science Teacher, 54(6), 46-48.

Kulik, C. L., \& Kulic, J. A. (1982). Effects of ability grouping on secondary school students: A meta-analysis of evaluation findings. American Educational Research Journal, 19(4), 415-428.

Manlove, J., \& Baker, D. (1995). Local constraints and opportunity to learn. In M. Hallinan (Ed.), Restructuring schools (pp. 133-153). New York: Plenun.

Matthews, D. J. (1997). Diversity in domains of development: Research findings and implications for gifted identification and programming. Roeper Review, 19, 172-177.

Slavin, R. (1987). Ability grouping and student achievement in elementary schools: A best-evidence synthesis. Review of Educational Research, 57(3), 293-336.

Xanthou M., \& Pavlou, P. (2008). Strategies of accommodating mixed ability classes in EFL settings: Teachers' Armour in an ongoing battle. Retrieved from http://old.hltmag.co.uk/jan08/mart04.htm 